\title{
Usability analysis of industrial cooking equipment
}

\author{
Calado, Alexana Vilar Soares ${ }^{a^{*}}$ and Soares, Marcelo Márcio ${ }^{b}$ \\ ${ }^{a}$ Department of Design - Faculty of Boa Viagem - Jean Emile Favre street, 422 - Imbiribeira, 51200-060 \\ - Recife, Pernambuco - Brazil \\ ${ }^{b}$ Center for Arts and Communication, Federal University of Pernambuco, Moraes Rego avenue, Cidade \\ Universitaria Sn 50670-420 - Recife, Pernambuco - Brazil
}

\begin{abstract}
This paper refers to the comparative study of the equipment used for cooking in commercial of kitchens restaurants that use the system of traditional cooking and those ones which use the system called smart cooking (combination oven). The study investigates the usability issues concerning to the two systems, analyzing comparatively the aspects related to anthropometry, dimensional variables, the use of the product and also the product safety, as well as issues of information related to operation of the new concepts of cooking in intelligent systems.
\end{abstract}

Keywords: Ergonomics, Usability, industrial kitchen, industrial cooking

${ }^{*}$ Corresponding author. E-mail: alexanavilar@gmail.com 


\section{Introduction}

The assumptions for developing the design of a product must embody the core values of usability within the limits of human action, providing a more feasible material world with reality. Usability is an issue that requires an understanding of how simple and easy is the use of the product, how "friendly" is the product for its user, as suggested by Iida [2]. According to the author, usability is related to the comfort and efficiency of products, however it does not only depend on the product but as well also as depends on the user, the intended objectives and the environment in which the product is used. In summary relates to the product, and to user.

The kitchen forms an ordered set of equipment and facilities seamlessly integrated to the production of food (meals). For the system to work within this perspective, a detailed study of its facilities, materials to be used, the provisions of layout, appropriate working methods and relations of usability of their equipment, it becomes indispensable.

The kitchen, as a system, should be a function for the target public, the location and service between production and sale of the product should be perfect. Any mistake occurred in this route will cause a decrease I $n$ quality of service, causing dissatisfaction to the consumer. [6]

In addition to an appropriate layout, another aspect of great importance for the optimal use of a kitchen are the issues related to the size, safety management and industrial kitchen equipment, which directly interfere with the usability of these products. $[3,1]$

According to Silva Filho [6], the kitchens today, must be based on (I) the rationalization of the methods of food production, (II) in reduction of operating costs, (III) quality control of the final product (IV) in reducing areas of production and expansion of areas for the client and $(\mathrm{V})$ in conservation, transportation and safe storage. This way the kitchen will support improvement of techniques and services to better customer service.

Adapt the layout (physical arrangement) to each function means to reduce production costs, process time, improved use of available space, resulting in increased productivity. The arrangement results in adequate physical organization of the physical facilities of the company from the efficient use of equipment, materials, people and effective processing power via the shortest distance in the shortest possible time and space.

In recent years environmental changes have determined the increasing competitiveness among companies in the kitchens. Significant changes have occurred for the high cost and management difficulties that have the manpower, aspects related to quality, hygiene and health of prepared foods, including still matters regarding to rules of this sector [5]. The new Technological innovations coming up involve equipment, food products and production processes. These new equipment contain differences mainly related to transmission of heat through cooking and cooling equipment. Cook chill technology (cooking / cooling) is to cook food at a temperature of $70^{\circ}$ for more than five minutes and cool it rapidly to $30^{\circ}$, allowing the maintenance, consistency and nutritional value of foods with lower risk of contamination.

The objective of this research is to evaluate usability of the system compared to traditional cooking and intelligent cooking system, highlighting their similarities and differences and the contributions that the new system has brought to this sector, from evaluation of inquiry and observation of users of the equipment for cooking.

The presentation and discussion of research data was divided into two stages. In the first step, we present the results of the analysis and interviews with officials of the kitchen and searched the second stage analysis and present the results of questionnaires to employees in the cooking of all kitchens researched.

\section{Research methodology}

The methodological procedures used in this research using part of the method proposed by Moraes and Mont'Alvão [4]. For users of inquiry, a total of 53 staff, including: eight chefs, 12 cooks and kitchen helpers 33, underwent interviews and questionnaires addressing issues relating to product characteristics such as functionality, maintenance and cleaning and ease of operation, product safety: accidents suffered while handling the product, degree of discomfort and danger of accidents caused while performing the task in relation to the product search after the search result, we applied the correlation test.

The field study was conducted in three commercial kitchens of restaurants located in the city of Recife, which caters to the socioeconomic bands $\mathrm{A}$ and $\mathrm{B}$, three commercial kitchens of restaurants, which serve the same niche customers located in the city of São Paulo.

In this study, quantitative analysis was performed by observation of the data obtained from the different techniques applied and evaluation of open questions. The quantitative 
1060

analysis was made from statistical tests of correlation.

\subsection{Strategy and design}

The interviews were conducted in the workplace of each volunteer during the intervals of their work and lasted approximately 20 minutes per participant. The purpose of the application of the interview was to collect specific information of the products surveyed (industrial stove and oven combination) from the perspective of user equipment.

After a brief introduction about the research in question, respondents answered all questions individually. In the beginning was observed among participants, some concern over the content of the questions, probably for fear of some future rebuke from boss. At this point the researcher reinforced the character of scientific research and ensuring the confidentiality of the data presented.

The final version of the questionnaire, containing open and closed questions about working conditions with the equipment surveyed was personally delivered to each participant. At the time of delivery was a brief explanation of the research objectives, the need to fill out the Informed Consent and informed and content of the questionnaire. Questionnaires delivered in the city of São Paulo has the largest return period, which occurred via SEDEX. Questionnaires delivered in Recife were returned within 15 days or so.

\subsubsection{Research data}

The age of respondents ranged from 21 to 55 with an average of 33 years. 94.3\% [ $f=50]$ were men and $5.7 \%$ [ $\mathrm{f}=3]$ were women. We must draw attention to the employees of the restaurants surveyed are mostly composed of men, however, notes that this percentage has been modified in recent years with the gradual entry of women in this market.

The education level of participants, it was observed that users of industrial stove $43.3 \%$ [f $=13]$ have an incomplete high school, $16.7 \%$ [ $\mathrm{f}$ $=5]$ attended the 1 st grade, $13.3 \%[f=4]$ have the incomplete grade $2,16.7 \%$ [ $f=5]$ completed the second grade, $6.7 \%[2=\mathrm{f}]$ have the $3 \mathrm{rd}$ degree incomplete and $3.3 \%$ [ $\mathrm{f}=1$ ] has a college degree.

The users of the combination oven only $9.1 \%[\mathrm{f}=2]$ possess a high school incomplete, $13.6 \%[f=3]$ completed a degree, $4.5 \%[f=1]$ have the 2 incomplete high school, $45.5 \%$ [f + 10 ) completed the 2 nd grade, $9.1 \%$ [2 = f] have the 3rd degree incomplete and $18.2 \%[f=4]$ completed the degree. Clearly the difference in the percentage level of schooling by researching product. In the case of industrial use of the stove the highest percentage of level of education reported was an incomplete primary education, whereas for the combination oven was second. schooling. We realize that the difference between the level of education of users of both systems, probably due to the need to assimilate information more complex for the operating system with the intelligent cooking.

\section{Applications and results - interviews}

\subsection{Industrial stove}

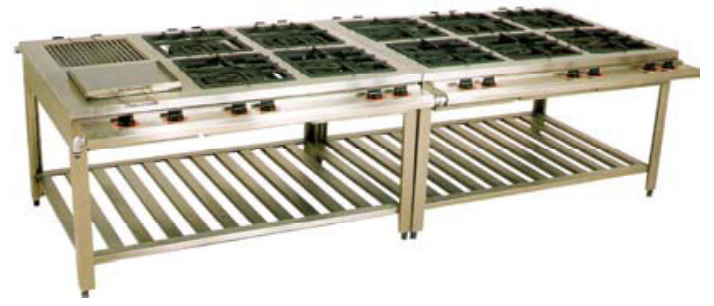

Figure 1: Example of an industrial stove market Source Catalog manufacturer - COZIL, 2007

Introductory question as to contextualize the research and confirm the initial information was asked about the performance of the equipment

When asked about the performance of the industrial stove, the stove all answered that perform well, however after the positive response placements appeared on the functioning of the same, showing that the equipment had performance problems, despite the positive response, as can be seen in the comments: "The firing of the burners should be done automatically, because the use of alcohol gel is not very secure, requires close attention not to cause accidents," "It has happened inexperienced employee trigger button for firing and take to put alcohol gel, making fire rise uncontrollably, "'" When the stove is working with all the burners lit, the atmosphere is very hot, especially around the waist down. "

On being asked about the difficulties of using industrial stove, a majority $(89.71 \%, \mathrm{n}=$ 16) of respondents made reference to cleaning, cargo transport and accessibility of facilities, some comments were: "The cleaning is done daily with a special product, but it is not so clean as well, because it has many places difficult to clean, only at the end of the day (night) is that the cleaning is complete, "" Sometimes when we clean the stove, uncontrolled flames burners, "regarding the transportation of cargo that was placed" The very heavy pots (pots) must be carried by two people, even though she (person) is large or small. " 
As for accessibility, the difficulty of reaching the pans (SOTE) under the stove was mentioned by all participants: "In reality, we get used to catch the SOTE down, kneeling down, we just feel the same when it comes end of the workday."

When asked about the occurrence of accidents in the industrial stove, a majority of respondents $(77.33 \%, \mathrm{n}=14)$ answered that they had never suffered any serious accident, only minor burns possible, some comments made were: "The Splash of hot oil and sauces always burn the hands and arms". One respondent mentioned that the serious accident he witnessed was due to lack of alertness. Yet another employee reported that he fell down in the kitchen, because the wet floor reached into a pan of hot oil, causing a serious burn on the hand. When asked about the occurrence of pain in the body while performing the task with the industrial stove absolute majority $(n=18.100 \%)$ of respondents feel pain in the inferior limbs at the end of the journey. Also mentioned was the existence of headaches and pain in the upper limbs, due to the constant manipulation of the pans as we present some comments: "normally at the end of the workday we feel pain in the legs, we get a lot of time standing, and into hard day we feel of pain in arms, too, "' You feel pain in the legs and head, sometimes I'm at home resting and still hear the noise from the kitchen at work."

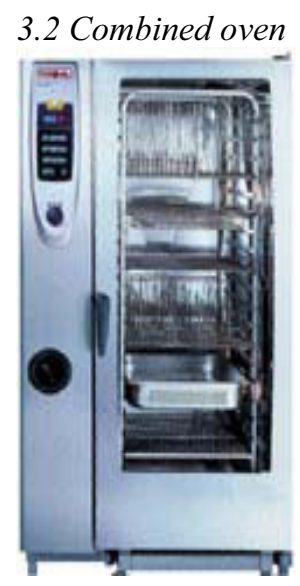

Figure 2: Example of a combination oven Source: Manufacturer's catalog - RATIONAL, 2007

When asked about the performance of equipment, all respondents agreed enthusiastically that the oven served very well the expectations of working and a few comments are listed below: "You choose the option that you want to do and it determines the cooking time and does everything almost itself, " I have worked with the combination oven for 10 years and I think it only came to add, you can better control the quality of the dish, trim control, if the point is crispy ...", "It's evolution of kitchen, you hit the whole process of cooking the traditional stove and with more control in less time. "

When asked about the difficulties of using the product of the total respondents $(100 \%, \mathrm{n}=$ 18) responded that only the beginning, adapting the use of combination oven, they felt a certain reluctance to operate it. But said all that learning was not complicated and the system equipment is top-explanatory and therefore makes its use easier.

On being asked about the occurrence of accidents combined with the oven, the absolute majority $(100 \%, \mathrm{n}=18)$ of respondents who had never experienced any kind of accident combined operating the oven.

When asked if any part of the body was affected while performing the task of cooking with the oven combination, $(33.27 \%, \mathrm{n}=6)$ mentioned the fact that the work performed during a long period of standing, and therefore felt pain legs and feet at the end of the day's work. However, the majority $(66.73 \%, n=12)$ of respondents said they did not feel any pain in the task: "The cart (mobile structure, which is part of the combination oven) made easier the movements of GN (the containers that are put in the oven) is not necessary to carry the heavy pots with hands like we did with the industrial stove."

When asked of the difficulties in understanding the information generated by the system, more than half $(58.25 \%, \mathrm{n}=10)$ of the respondents mentioned that sometimes there are problems of operation and in these moments that a technician had to be there to normalize situation. Some comments on problems in the operation were: "A month ago, on the digital panel of the furnace appeared a message asking to close the door when the door was closed, but the system did not recognize the information that the door was closed and did not start operation, "" On one occasion the panel alerted to inject gas when the furnace runs combined electricity or gas, what happened in this episode is that there was a power outage in the area."

When asked about the clarity of the information generated by the operating system combination oven, all participants have mentioned the importance of constant training and suitable for the operators of this system, once trained, the interface with the equipment is much easier.

\section{4. - Applications and results questionnaires}

4.1 Characteristics of product use - industrial stove / oven combination 

ease.

When analyzing the degree of importance perceived by users in relation to the characteristics of the product showed that for employees who operate the stove industry, the most important characteristic considered in regard to product safety is investigated $(86.7 \%)$ , followed by ease of use $(76.7 \%)$, functionality $(66.7 \%)$, comfort $(60.0 \%)$ and reliability $(53.3 \%)$, as shown in Figure 3.

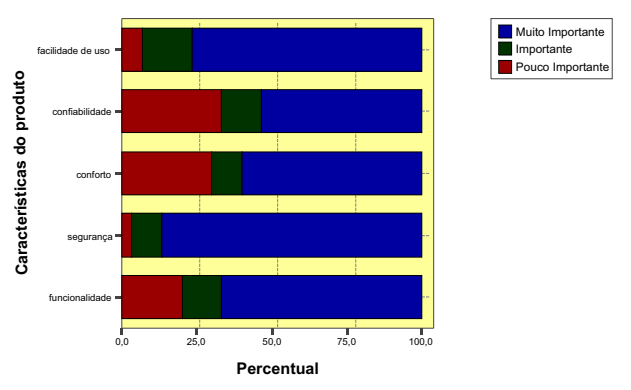

Figure 3: Graph degree of importance of product characteristics (industrial oven)

In the opinion of staff that use the combination oven, the most important features in relation to the product search are: security $(100.0 \%)$ and reliability $(100.0 \%)$, followed by functionality $(95.7 \%)$, comfort $(91.3 \%)$ and ease of use $(91.3 \%)$, see graph in Figure 4.

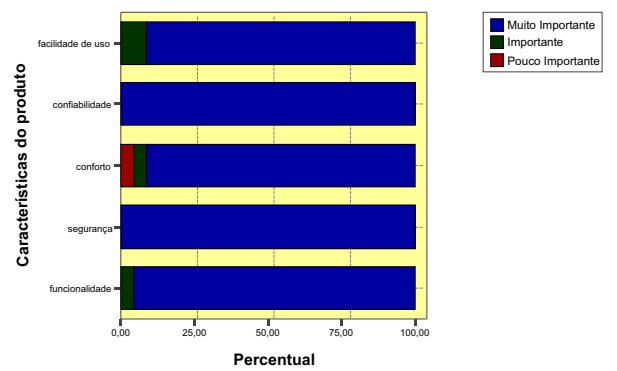

Figure 4: Graph characteristics (combination oven degree of importance of product)

According to research presented, half of the industrial stove users interviewed have experienced some kind of difficulty using the equipment, while for users of combination oven, only $17 \%$ of respondents have felt some sort of difficulty in operating the equipment . Here it is observed some disparity on the issue of product use, the oven presents combined, according to the survey, with the potential usability (expressed from the difficulty of use) than the industrial stove.

It was observed that $56.7 \%$ of users who work with the stove Industrial experience difficulty when performing cleaning and maintenance of equipment, while for $87.0 \%$ of users of the combination furnace cleaning and
Again, it is found that the product combination furnace is rated more positively by respondents than the industrial stove. This is probably due to the fact that present a combination oven cleaning system.

It was found that $63.3 \%$ of the industrial stove operators claimed to have felt some kind of difficulty in understanding the operation of equipment, while $95.5 \%$ of the furnace operators combined, respondents did not feel any difficulty in understanding the functioning of equipment. Once again the assessment by respondents of this survey, the product was more favorable combination oven.

According to the survey most $[f=23$, $76.7 \%$ ] of users of industrial stove considered the height of the equipment is suitable for the operation of the product, $20.0 \%$ considered regular and $3.3 \%$ considered the inadequate to use. In relation to depth, most $[f=23,76.7 \%$ ] opined that the depth is adequate, $16.7 \%$ considered regular and $6.7 \%$ considered the inappropriate height. The scope, most $[f=21$, $70.0 \%$ ] considered this item as being good, $23.0 \%$ as fair and $6.7 \%$ as poor.

In relation to the surface fitting of the stove industry, the vast majority $[\mathrm{f}=25,83.3 \%$ ] found that the lining of the equipment was suitable for use, $23.3 \%$ felt that the fitting could be improved and $3.3 \%$ the fitting of the equipment regarded as poor.

In research with the combination oven, almost all $[\mathrm{f}=22,95.7 \%$ ] of users considered that the height of the equipment is adequate for its operation. As the depth at most $[\mathrm{f}=21$, 91.3\%] considered appropriate, the extent all of them gave their opinions and be suitable for use and in relation to fitting most of the product $[\mathrm{f}=$ 21, 95.5\%] also considered appropriate.

Once again the combination oven is rated positively by participants, in relation to various items related to product usability.

When asked, users of industrial stove, on the occurrence of accidents using equipment $66.7 \%$ responded positively, while $33.3 \%$ reported ever having experienced any type of accident using the product.

In answering the same question, $90.9 \%$ of users reported that the combination oven never suffered any kind of accident, while 9.1\% admitted having had an accident using the product.

It was observed that the answers are exactly opposite to the comparison of accidents between the industrial stove and oven combination.

According to the study, $96.7 \%$ of the industrial stove users interviewed said they perform repetitive movements during the task of 
cooking, while only $13.0 \%$ of the furnace operators confirmed the combined performance of repetitive movements during the task.

It was identified during the unsystematic observations of the kitchens that work with the intelligent cooking that while filling the GN to be placed in the oven combined, there was the performance of repetitive movements by the user, although it has not been confirmed in the responses questionnaires.

According to the survey $63.3 \%$ of users of industrial stove perform sudden movements during task performance which can cause serious musculoskeletal disorders, while users of the combination oven only $8.7 \%$ said they make sudden movements. According to the study $93.3 \%$ of users said they conduct industrial stove physical effort while performing the task of cooking, while $82.6 \%$ of the combination furnace operators have responded not to make physical effort.

Again a strong index of usability is seen in smart cooking equipment from the viewpoint of the research participants.

According to the present study, $86.7 \%$ of the industrial stove users interviewed claimed to be mental effort required to operate the equipment, while $73.9 \%$ of the user claim not necessary mental effort to perform the task of cooking this equipment.

He was appointed during the non-systematic observations carried out in kitchens surveyed, employees of traditional cooking show is pressured by the intense pace of work by the following aspects: the demand of orders to be fulfilled in a short time, the constant request of memories and long-term and constant attention by the request that this task requires. This is due to the fact that the user is forced to constantly using short-term memory (to memorize the order of entry of orders), the long-term memory (used to remember the way to prepare the dish request), in addition to time factor that acts directly on the user, making it a considerable mental stress.

According to the respondents $60 \%$ of operators said industrial stove pain at some point during the execution of the task of cooking, while $95.7 \%$ of users showed the combination oven not feel any pain while performing the task.

Participants were asked to sample $[\mathrm{n}=53]$ to answer if they feel pain / discomfort or not in different parts of the body at the beginning of the journey (this information is important to try to identify if the operators already arrived at work feeling some pain) in the middle and end of the workday.

The responses represented the regions of the body where you feel more pain than the use of equipment in case of industrial stove shows that in the early hours of the few users claimed to feel some discomfort, but during the workday, the pain perception was being expanded. At the end of the day more than half of employees surveyed reported feeling pain in the feet. The areas mentioned by respondents with the highest rate of pain were the feet, ankles, legs, back, bottom, eyes, back, head and neck.

In relation to the combined the parts of the body furnace in which the user feels more pain / discomfort in using the equipment, the results differ from results regarding the use of industrial stove. Only an insignificant portion of respondents reported feeling pain while performing the task with the combination oven.

\section{Conclusion}

It was observed that the responses in interviews and questionnaires applied by the participants do not always correspond to what was observed in the case study. This is what happened especially in relation to assessment by the users of the system of intelligent cooking, the oven got combined in almost $100 \%$ of the questions regarding its usability while a positive score on the observation of the task of cooking with this product, were noted some ergonomic demands not mentioned by the research participants, such as:

- Occurrence of improper handling, bending, rotation and inclination of the back. This was observed when the placement of the structures GNs on the shelves that go in the oven combined. Both at the time of filling the shelf closest to the ground, and in the highest. Both are located outside the envelope of reach of the user.

- At the time of assembly of the GN, it is observed that the employee flexes the cervical and upper thoracic regions during the task, applying excessive force in handling the longhandled ladle.

- Because it is a highly complex system, in the event of a system crash, you can only operate on it again after consulting a specialist, which may not occur within keeping with the operation of the kitchen.

- In furnaces that run on electric power, the power supply falls, cause dramatic stops in the process of assembling the meals, which can cause delays in service delivery.

In the case of the stove Industrial much of the problems raised in the case study were also mentioned in the responses of participants can be compared as follows:

- Constraints arising from the design of the equipment shelf for storage of utensils (SOTE, a 
kind of frying pan) located very close to the ground, forcing the user to perform flexion / rotation / steep slope of the spine.

- The completion of the task does not allow switching position, demanding that the worker stay standing for long periods. Employees working on foot throughout the workday. - During the workday, employees at times with large volumes carry pots on the stove, there is no type of aid for this function to perform this type of physical effort likely to aggravate the injury.

- The heat produced by heat exchange caused by the burners of the stove causes a discomfort that is reflected in the constant sweating framework presented by the cooking staff.

- The invisibility of the flame of natural gas from the burner when lit, can cause a misunderstanding by the user and could cause a combustion, the same may occur in relation to the use of alcohol gel, which is used in lighting the burners.

The correlation test used in this study indicated a strong correlation between the two equipments surveyed as can be seen below: The hypothesis is proven correlation between the industrial stove and oven combination, when it comes to relationship difficulties in cleaning product. The combination oven by having an automated cleaning process frees the user from physical wear that occurred in this task when it is done on the stove industry.

We verified a correlation between industrial stove and oven combination regarding the difficulty in understanding how the product works. The vast majority of users of the combined oven mentioned have no difficulties in understanding the operation of equipment, which has not happened with the industrial users of the stove, when more than $60 \%$ of respondents admitted to having difficulty understanding how the product works, we believe that this result may be related to differences in educational level among users of both systems.

Evidence of correlation between the industrial stove and oven combination in relation to the incidence of accidents involving the two products, when reporting the issue $90 \%$ of users responded combination oven has never suffered any accident using the equipment, while industrial stove users $66.7 \%$ have been subject to some kind of accident, this result suggests that the intelligent cooking equipment is safer.

It was also observed a correlation between industrial stove and oven combination regarding the difficulty in understanding how the product works. The vast majority of users of combination ovens mentioned no difficulty in understanding the operation of the equipment. This has not happened with the industrial users of the stove, when more than $60 \%$ of respondents admitted to having difficulty understanding how the product works. We believe that this result may be related to differences in educational level among users of both systems.

Also in the aspect of durability of older products, was appointed a correlation between the products surveyed, almost $50 \%$ of the industrial stove users consider the products of today break more than the products of the past. The users of the combined oven, most responded negatively to this question. We feel that this may result is related to the short period of time in which this equipment is in the market.

Tests have shown a correlation between usability industrial stove and oven combination, these tests indicated that the combined operation of the furnace becomes repetitive in a few compared the use of industrial stove. There is also no occurrence of motion during the task combined with the oven, it was evaluated as a more comfortable operating equipment.

With respect to the requirement of physical effort to operate the product, it was noted the correlation between industrial oven or combination oven. It is noticed that the stove was evaluated as an industrial product where the demand for physical effort is far superior to the necessity of combination oven.

Regarding the mental effort required for operation of the product was also a marked correlation between the units surveyed, despite the cognitive demand of learning occurred when the initial operation of the programs used to perform the task of cooking with the oven combined. Still, its users believe that after this period, the system becomes "friendly", making it much easier task execution, while the traditional system, users consider to be mental effort required to perform it, due to the constant use of memory of short and long term, coupled with the stress from the limited time to complete the task.

The last correlation indicated between the two systems refers to the discomfort that occurred during the use of equipment. As the correlation test, when using the stove industry to accomplish the task of cooking, the subjects are more vulnerable to suffer physical discomfort that users of the combination oven.

The result of inquiry addressed to users of the systems allows us to see that operators in the view of the combination furnace stands as a most suitable equipment to carry out the task of cooking in kitchens. The performance assessment by the volunteers was very positive, which makes us believe that its final entry on 
the market is only a matter of time solving the equation versus the product cost.

\section{References}

[1] Cushman, W. H \& Rosenberg, D. J. Human Factors in product design. Elsevier, Amsterdam, 1991

[2] Iida, I. Ergonomics: Design and production. @nd. Ed. São Paulo: Edgard Blücher, 2005.

[3] Jordan, P.W. An introdution to Usability.Taylor \& Francis, 1998.

[4] Moraes, Anamaria \& Mont'Alvão, Claudia. Ergonomics: Concepts and Applications. Rio de Janeiro, RJ. Ed 2AB, 2003.

[5] Proença, R.CP.C. Technological innovation in collective food production. 2nd. Ed Florianópolis: Insular, 2000 [6] Silva Filho, R. A. Basic Manual for Planning and Design of Hotels and Restaurants. Recife: Universitária UFPE, 2001 